\title{
The potential application of electrophysiology diagnostics and therapeutics in acute heart failure syndromes
}

\author{
Norman C. Wang • Gregg C. Fonarow • \\ Mihai Gheorghiade
}

Published online: 26 April 2011

(C) Springer Science+Business Media, LLC 2011

A major conundrum in the management of acute heart failure syndromes is the observation that patients are generally treated successfully during the in-hospital phase, but have a markedly high post-discharge event rate $[1,2]$. The 30 -day readmission rate has remained fairly constant or increased over the last decade at approximately $25 \%[3,4]$. Over one-third of patients hospitalized for acute heart failure syndromes are dead 1 year after discharge [3]. Despite fairly successful implementation of heart failure performance metrics in recent years, there has been no significant improvement in these outcomes [5]. It has become clear that our current state-of-the-art care of patients with heart failure exacerbation is not sufficient.

Many patients with heart failure have co-existing heart rhythm disorders. Few systematic evaluations of electrophysiology diagnostics and therapeutics have been performed in patients in the acute heart failure setting. As arrhythmias can be precipitants of heart failure exacerbations or contribute directly to mortality, optimizing management may provide a significant opportunity to improve outcomes. This issue of Heart Failure Reviews contains seven articles that focus on select topics dealing with how

N. C. Wang

Cardiovascular Institute, University of Pittsburgh Medical

Center, Pittsburgh, PA, USA

G. C. Fonarow

Ahmanson-UCLA Cardiomyopathy Center, Los Angeles, CA, USA

M. Gheorghiade $(\bowtie)$

Center for Cardiovascular Innovation, Northwestern University

Feinberg School of Medicine, 645 North Michigan Avenue,

Suite 1006, Chicago, IL 60611, USA

e-mail:m-gheorghiade@northwestern.edu tools available in the management of heart rhythm disorders may potentially be applied to patients hospitalized for or recently discharged from a hospitalization for heart failure.

Many patients who present with worsening heart failure already have an implanted device with pacing functionality. Marc Lahiri, Justin Mao, and Claudio Schuger discuss pacemaker parameters that may interact with heart failure status. They specifically focus on the issues of right ventricular pacing burden, atrioventricular timing, and interventricular timing. Theoretically, adjusting these parameters in the decompensated patient may be of benefit. They propose two algorithms to assess pacing parameters in patients who present with heart failure, with and without atrial fibrillation.

Many patients with heart failure and reduced left ventricular ejection fraction (LVEF) have an implantable cardioverter-defibrillator (ICD). Arrhythmias that often accompany heart failure deterioration may lead to appropriate and/or inappropriate ICD shocks. Although potentially life-saving in cases of ventricular arrhythmias, these shocks are often extremely painful. Jason Bradfield, Roderick Tung, Noel Boyle, and Kalyanam Shivkumar explore the management of ICD shocks with an emphasis on medical therapy, ICD programming, and catheter ablation.

Despite the prevalence of atrial fibrillation and heart failure, there are little data to direct the management of patients who present with both conditions [6, 7]. Pacemaker implantation with catheter ablation of the atrioventricular junction represents the ultimate treatment for patients with medically refractory rapid ventricular rates. It is highly effective, but is both invasive and permanent. Jason Rubenstein and James Roth provide an in-depth discussion of the potential benefits and risks of this therapy in acute heart failure patients. 
Catheter ablation has become a major therapeutic option for many patients with arrhythmias. These procedures are typically performed in patients who are otherwise medically stable. While generally safe, performing ablation in patients who are hospitalized with acute heart failure adds additional peri-procedural risk. Bradley Knight and Jason Jacobson discuss the potential role of catheter ablation of arrhythmias that are most likely to be of significance in those with acute heart failure. Patient selection and procedural timing are of particular importance.

Approximately half of patients with acute heart failure have reduced LVEF and are thus potential candidates for ICDs. These devices are highly effective in treating sudden arrhythmic death. Implanting these devices in patients has most systematically been evaluated in patients with chronic, stable heart failure status. Norman Wang, Jonathan Piccini, and Mihai Gheorghiade discuss the issue of timing of ICD insertion in patients who are hospitalized with acute heart failure and are known to have a chronically reduced LVEF.

Cardiac dyssynchrony, manifest as a prolonged QRS duration, is known to be a significant prognostic marker in patients with reduced LVEF [8]. Cardiac resynchronization therapy (CRT) is a particularly attractive therapy in the acute heart failure population as optimizing cardiac performance may significantly improve post-discharge death and rehospitalization. This intervention is not without risk, and there are no large scale studies of CRT implementation in this patient population. Norman Wang, Sanjoy Bhattacharya, and Mihai Gheorghiade discuss the potential benefits and risks of implanting patients with CRT devices during or soon after hospitalization for heart failure.

The issue of timing of insertion of an ICD, a CRT device, or a combination device in those with reduced LVEF who have not had a prior episode of aborted sudden death is of particular importance. The most recent American College of Cardiology and American Heart Association guidelines for the management of heart failure contain a new section on "The Hospitalized Patient" which discusses in-hospital treatment and discharge strategy, but does not address this important issue [9]. Of all available electrophysiology procedures, these have the most robust data demonstrating mortality benefit in heart failure patients with reduced LVEF. However, all of these trials were performed in the chronic, stable heart failure patient on optimal medical therapy [10-15]. By definition, patients who present with acute heart failure syndromes are not on optimal medical therapy. Current guidelines therefore recommend sustained LVEF reduction in the presence of an optimized medical regimen, which could take months to achieve, before they should be considered for these devices. The stark reality is that patients may not live long enough to be candidates for these potentially life-saving devices under these current recommendations. More research is needed to determine which patients have the potential to benefit from early intervention.

In contrast to the first six articles of this issue, a number of studies have evaluated the use of device monitoring diagnostics in the acute heart failure population. Michael Samara and Wilson Tang provide a comprehensive summary of the studies that have been published to date. They discuss which situations are the most likely to benefit from this technology and what diagnostic features are most likely to lead to improved outcomes.

Despite current recommendations for the management of acute heart failure patients, high rates of readmission and mortality still occur. The articles contained in this issue provide an overview of many pertinent electrophysiology issues that may have clinical importance. The majority of these modalities still require more systematic study to determine safety and efficacy. Nevertheless, we hope our readers will share our enthusiasm at the potential to markedly benefit these most challenging patients.

\section{References}

1. Gheorghiade M, Zannad F, Sopko G, Klein L, Piña IL, Konstam MA, Massie BM, Roland E, Targum S, Collins SP, Collins SP, Filippatos G, Tavazzi L (2005) International working group on acute heart failure syndromes acute heart failure syndromes: current state and framework for future research. Circulation 112:3958-3968

2. Gheorghiade M, Pang PS (2009) Acute heart failure syndromes. J Am Coll Cardiol 53:557-573

3. Curtis LH, Greiner MA, Hammill BG, Kramer JM, Whellan DJ, Schulman KA, Hernandez AF (2008) Early and long-term outcomes of heart failure in elderly persons, 2001-2005. Arch Intern Med 168:2481-2488

4. Ross JS, Chen J, Lin Z, Bueno H, Curtis JP, Keenan PS, Normand ST, Schreiner G, Spertus JA, Vidán MT, Wang Y, Wang Y, Krumholz HM (2010) Recent national trends in readmission rates after heart failure hospitalization. Circ Heart Fail 3:97-103

5. Fonarow GC, Peterson ED (2009) Heart failure performance measures and outcomes: real or illusory gains. JAMA 302:792-794

6. Al-Habeeb W, Al-Admawi M (2009) Managing patients with rapid atrial fibrillation and decompensated heart failure. Circ Heart Fail 2:71

7. DiMarco JP (2009) Atrial fibrillation and acute decompensated heart failure. Circ Heart Fail 2:72-73

8. Wang NC, Maggioni AP, Konstam MA, Zannad F, Krasa HB, Burnett KC Jr, Grinfeld L, Swedberg K, Udelson JE, Cook T, Traver B, Zimmer C, Orlandi C, Gheorghiade M (2008) Efficacy of vasopressin antagonism in heart failure outcome study with tolvaptan (EVEREST) investigators. clinical implications of QRS duration in patients hospitalized with worsening heart failure and reduced left ventricular ejection fraction. JAMA 299:2656-2666

9. Hunt SA, Abraham WT, Chin MH, Feldman AM, Francis GS, Ganiats TG, Jessup M, Konstam MA, Mancini DM, Michl K, Oates JA, Rahko PS, Silver MA, Stevenson LW, Yancy CW (2009) 2009 focused update incorporated into the ACC/AHA 2005 guidelines for the diagnosis and management of heart 
failure in adults: a report of the American College of Cardiology Foundation/American Heart Association Task Force on practice guidelines. J Am Coll Cardiol 53:e1-e90

10. Moss AJ, Zareba W, Hall WJ, Klein H, Wilber DJ, Cannom DS, Daubert JP, Higgins SL, Brown MW, Andrews ML (2002) Multicenter automatic defibrillator implantation trial II investigators. N Engl J Med 346:877-883

11. Bardy GH, Lee KL, Mark DB, Poole JE, Packer DL, Boineau R, Domanski M, Troutman C, Anderson J, Johnson G, McNulty SE, Clapp-Channing N, Davidson-Ray LD, Fraulo ES, Fishbein DP, Luceri RM, Ip JH (2005) Sudden cardiac death in heart failure trial (SCD-HeFT) investigators. amiodarone or an implantable cardioverter-defibrillator for congestive heart failure. N Engl J Med 352:225-237

12. Bristow MR, Saxon LA, Boehmer J, Krueger S, Kass DA, De Marco T, Carson P, DiCarlo L, DeMets D, White BG, DeVries DW, Feldman AM (2004) Comparison of medical therapy, pacing, and defibrillation in heart failure (COMPANION) investigators. cardiac-resynchronization therapy with or without implantable defibrillator in advanced chronic heart failure. N Engl J Med 350:2140-2150

13. Cleland JGF, Daubert J-C, Erdmann E, Freemantle N, Gras D, Kappenberger L, Tavazzi L (2005) Cardiac resynchronizationheart failure (CARE-HF) study investigations. The effect of cardiac resynchronization on morbidity and mortality in heart failure. N Engl J Med 352:1539-1549

14. Moss AJ, Hall WJ, Cannon DS, Klein H, Brown MW, Daubert JP, Estes NAM 3rd, Foster E, Greenberg H, Higgins SL, Pfeffer MA, Solomon SD, Wilber D, Zareba W (2009) MADIT-CRT trial investigators. Cardiac-resynchronization therapy for the prevention of heart-failure events. N Engl J Med 361:1329-1338

15. Tang ASL, Wells GA, Talajic M, Arnold MO, Sheldon R, Connolly S, Hohnloser SH, Nichol G, Birnie DH, Sapp JL, Yee R, Healey JS, Rouleau JL (2010) Resynchronization-defibrillation for ambulatory heart failure (RAFT) investigators. Cardiacresynchronization therapy for mild-to-moderate heart failure. N Engl J Med 363:2385-2395 